\title{
Study of recent and future trends in place of death in Belgium using death certificate data: a shift from hospitals to care homes
}

\author{
Dirk Houttekier ${ }^{1 *}$, Joachim Cohen ${ }^{1}$, Johan Surkyn² and Luc Deliens ${ }^{1,3}$
}

\begin{abstract}
Background: Since most patients prefer out-of-hospital death, place of death can be considered an indicator of end-of-life care quality. The study of trends in place of death is necessary to examine causes of shifts, to evaluate efforts to alter place of death and develop future policies. This study aims to examine past trends and future projections of place of death.

Methods: Analysis of death certificates (decedents aged $\geq 1$ year) in Belgium (Flanders and Brussels Capital region) 1998-2007. Trends in place of death were adjusted for cause of death, sociodemographic characteristics, environmental factors, numbers of hospital beds, and residential and skilled nursing beds in care homes. Future trends were based on age- and sex-specific mortality prognoses.

Results: Hospital deaths decreased from $55.1 \%$ to $51.7 \%$ and care home deaths rose from $18.3 \%$ to $22.6 \%$. The percentage of home deaths remained stable. The odds of dying in a care home versus hospital increased steadily and was 1.65 (95\%Cl:1.53-1.78) in 2007 compared to 1998. This increase could be attributed to the replacement of residential beds by skilled nursing beds. Continuation of these trends would result in the more than doubling of deaths in care homes and a decrease in deaths at home and in hospital by 2040.

Conclusions: Additional end-of-life care resources in care homes largely explain the decrease in hospital deaths. Care homes will become the main locus of end-of-life care in the future. Governments should provide sufficient skilled nursing resources in care homes to fulfil the end-of-life care preferences and needs of patients.
\end{abstract}

\section{Background}

Place of death is considered an important indicator of quality of end-of-life care. Death in the usual place of residence is associated with the presence of family and friends, comfort and a feeling of control [1]. Most patients prefer to die at home, but in cases of inadequate pain control or when the burden becomes too great for family caregivers, end-of-life care and death in an institution may be preferred [1,2]. Place of death also has important consequences for health care costs, as end-of-life care in hospitals is more expensive than in care homes or at home $[3,4]$. Nevertheless, in Belgium and most other countries a majority of patients still die in hospital [5-7]. For reasons of cost and quality of care

\footnotetext{
* Correspondence: dirk.houttekier@vub.ac.be

'Vrije Universiteit Brussel, End-of-Life Care Research Group Ghent University

\& Vrije Universiteit Brussel, Laarbeeklaan 103, 1090 Brussels, Belgium

Full list of author information is available at the end of the article
}

supporting out-of-hospital death has become an important policy objective[8,9]. In Belgium and elsewhere, different models of palliative care services and options for out-of-hospital death have been developed $[9,10]$, but their effectiveness remains unclear.

Studying trends in place of death is necessary to monitor and gain insight into the reasons for changes to evaluate efforts to alter place of death, and to plan future end-oflife care services and facilities. Many previous studies were restricted to cancer patients [11-15] and only considered trends in home or hospital death although, with ageing of the population in developed countries, other chronic lifelimiting conditions will become more important (e.g. dementia related diseases) [16] and end-of-life care in care homes will become a major concern because of the expected increase in care home residents. In most studies, shifts in place of death were only related to shifts in age, sex and underlying cause of death [14,17-23], and shifts in

\section{C) Biomed Central}


other factors were not taken into account, e.g. in living arrangements, educational attainment, urbanization levels, and available care options. Although instituted in 1985, palliative care services in Belgium have been only gradually integrated into formal health care and reimbursed by healthcare insurance since 1997 [9,24]. Studying trends in place of death from 1998 to 2007 allows discussion of the impact of the growing availability of palliative care services and out-of-hospital end-of-life care options on an important patient outcome.

The aim of this study is to examine past trends between 1998 and 2007 and future trends until 2040 of place of death. The research questions are: 1) How did place of death change between 1998 and 2007 taking into account shifts in underlying cause of death, age, sex, living arrangement, educational attainment, urbanization level and availability of hospital and care home beds? 2) Did place of death change differently for specific subpopulations regarding living arrangement? 3) How would place of death change between now and 2040, based on trends between 1998 and 2007?

\section{Methods}

All deaths in Belgium (Flanders and Brussels Capital Region) aged one year or older in the period 1998-2007 were included $(\mathrm{N}=661773)$. A subpopulation of patients who died non-suddenly of one or more chronic life-limiting conditions (including cancer, cerebrovascular diseases, dementia, chronic obstructive pulmonary disorders, heart failure, diabetes, Parkinson's disease, chronic kidney disease, chronic liver disease, spinal muscular atrophy and related disorders, multiple sclerosis, neuromuscular disorders, and acquired immunodeficiency syndrome) and were thus eligible for palliative care (palliative subset) was considered in multivariate analysis $(\mathrm{n}=354$ 794) [16].

In Belgium, death certificates contain information about the place and cause of death and the sociodemographic characteristics of the deceased. Information about the place and cause of death is completed by a physician, who certifies the causal chain of diseases starting with the underlying cause of death, which is used in this study. Information about the sociodemographic characteristics (e.g. educational attainment, nationality, marital status, and living arrangements) is provided by the municipal institutions assisted by a relative of the deceased. Information from the death certificates is processed; the causes of death are coded in ICD-10 codes, and both medical and sociodemographic information is checked by a government agency [25]. Approval of an ethics committee to use death certificate data was not required, but in accordance with the Belgian Privacy Act, the use of the data was notified to the Belgian Commission for the Protection of Privacy.
Dependent variable is place of death recoded into four categories: home, hospital, care home and elsewhere. In Belgium, care homes are long-term care facilities, including both homes for the aged and skilled nursing facilities, although most have a mix of beds for residents requiring skilled nursing care on a daily basis (skilled nursing beds) and beds for those not requiring such care (residential beds).

The independent variables are the year of death (19982007), the illness of the deceased (underlying cause of death, recoded in six categories: cancer, cardiovascular diseases, respiratory diseases, diseases of the nervous system, stroke, and other using ICD-10 codes), the demographic (sex, and age: 1-64 years, 65-74 years, 7584 years, $\geq 85$ years) and social situation (educational attainment: no formal or elementary education, lower secondary, higher secondary, higher, and other or unknown), living arrangement (living alone, in a multiperson household or in an institution which is a care home in almost all cases), urbanization level (of the municipality of residence: very strong, strong, average, low or rural) and available hospital, and residential and skilled nursing care home beds (data on the availability of care home beds were provided by the Belgian National Institute for Health and Disability Insurance, data on hospital beds by the Federal Public Service of Health, Food Chain Safety and Environment). The availability of skilled nursing beds and residential beds in care homes was considered per 1000 inhabitants of 65 years or older in the community of residence or in areas of up to six smaller communities (115 areas in Flanders with an average population [year 2000] of 51654 inhabitants. Brussels Capital Region was considered one area) [26]. The availability of hospital beds was considered per 1000 inhabitants in areas of eight to 45 communities (14 areas in Flanders and Brussels Capital Region with an average population of 492826 )

For use in multivariate analysis, the underlying cause of death (cancer versus non-cancer chronic life-limiting conditions), education (no formal or elementary or lower secondary or unknown/other versus higher secondary or higher), and urbanization (very strong or strong versus moderate or low) were recoded into two categories.

Differences in trends in the total number of deaths (aged $\geq 1$ years) in the period 1998-2007 and the number of deaths in the palliative subset, the categories of cause of death, age, sex, living arrangement, urbanization level, and place of death were tested using $\chi^{2}$-test for trend.

Differences in trends in the total number of deaths (aged $\geq 65$ years) at home, in hospital, and in care homes and the number at home, in hospital, and in care homes of the categories of living arrangement were tested using $\chi^{2}$-test for trend. Differences in the yearly 
average availability of hospital, residential and skilled nursing beds were tested using the F-test.

Multivariate analyses were performed separately for those aged 65 years or older residing at home and those residing in care homes who died from chronic life-limiting conditions [16], because of differences in age and conditions in both subpopulations. Unadjusted odds ratios of the association of year of death and place of death were compared with odds ratios adjusted for underlying cause of death, age, sex, educational attainment, living arrangement, urbanization level, and available hospital beds, and residential and skilled nursing beds in care homes. The multivariate analyses were binomial logistic regression analyses with forward stepwise likelihood ratio selection procedure of variables and tested using the Wald-test for individual model parameters and model $-\chi^{2}$ for the whole model. The significance level was set at $\mathrm{p}=0.01$, given the large amount of data.

To examine which factors possibly adjusted the yearly trends in place of death, both logistic regression models were built up step by step. Starting from the unadjusted odds ratios of each year of death relative to 1998 for home death relative to hospital death and care home death relative to hospital death, we added the underlying cause of death, age, sex, educational attainment and living arrangement of the deceased, and the available residential and nursing beds in care homes and hospital beds step by step, to examine which of these factors adjusted the odds of dying in hospital in each year.

We used age- and sex-specific mortality projections of the Belgian National Planning Bureau for Flanders and Brussels Capital Region based on the population statistics of January 12007 to project future trends in place of death. Life expectancy at birth is expected to increase with 8 years both for men and women between 2007 and 2060, and to reach 85.3 years for men and 90.9 years for women [27]. These mortality projections were used to perform linear projections of future proportions and numbers of deaths from 2008 to 2040 in all care settings based on age- and sex-specific proportions of deaths in the different care settings we found in the period 1998-2007. Two scenarios were considered; in the first we examined future trends in place of death starting from the age- and sex- specific distribution in 2007, in the second we considered the age- and sex-specific percentage point changes in all categories of place of death from 1998 to 2007 [18].

All analyses were performed using PASW statistics 17.

\section{Results}

In 1998-2007, 661773 people (aged $\geq 1$ year) died in Belgium (Flanders and Brussels Capital Region), ranging from 64560 in 2006 to 68278 in 2003 (Table 1). The proportion of cancer deaths and deaths from diseases of the nervous system grew over that period, while deaths from cardiovascular diseases and stroke diminished. The proportion of deaths of the palliative subset increased from $54.2 \%$ to $55.1 \%$. The proportion of deaths of people aged 75 and over, with higher secondary or unknown education, living alone and in strongly or averagely urbanized places increased, while the opposite was true for deaths of people aged between 65 and 74, having no formal or elementary education, living in a multi-person household, and in very strong urbanized places. During the study period many residential beds in care homes were replaced by skilled nursing home beds. The average number of residential beds per 1000 inhabitants of 65 years or older fell from 56 in 1998 to 36 in 2007 while the average number of skilled nursing home beds rose from 12 to 29 . The average number of hospital beds per 1000 inhabitants remained stable.

The proportion of deaths in hospitals decreased from $55.1 \%$ in 1998 to $51.7 \%$ in 2007 (Table 2). In contrast, deaths in care homes increased from $18.3 \%$ to $22.6 \%$. Home deaths fell by $0.5 \%$ and the trend of home deaths differed insignificantly from the trend of the total number of deaths.

Hospital death rate declined (aged $\geq 65$ years) and care home death rate increased for all categories of living arrangement. The home death rate of people living alone or in multi-person households decreased and that of persons living in care homes increased (Figure 1). The decline of the hospital death rate was largest for those in care homes (from $31.0 \%$ to $21.5 \%$ ) (Figure 2), and was balanced by the increase in the care home death rate (from $66.8 \%$ to $75.3 \%$ ) (Figure 3 ) and home death rate (from $1.6 \%$ to $2.7 \%$ ). The care home death rate of people living at home increased, both of those living alone (from $5.7 \%$ to $8.9 \%$ ) and in a multi-person household (from $3.7 \%$ to $6.6 \%$ ).

The chances of dying in hospital for patients living at home did not decrease in 1998-2007 (Table 3). Stepwise adjustment (data not shown) of these unadjusted odds ratios showed no factors altered this trend. In our final model, the chance of dying out of hospital of those living at home was higher for cancer patients, those aged 85 or older, living in a multi-person household, living in moderate or low urbanized areas and in health care regions with less hospital beds. (Table 4)

Care home death was more likely in the period 19992001 compared with 1998, in 2002-2006 compared with previous years and again in 2007 compared with all previous years. (Table 3) This unadjusted trend of decreasing chances of care home residents dying in hospital was adjusted significantly by the increasing availability of skilled nursing home beds in care homes (data not shown). The other variables did not adjust the trend of 
Table 1 Population Characteristics of Deaths (aged $\geq 1$ y) 1998-2007 ( $N=661773$ )

\begin{tabular}{|c|c|c|c|c|c|c|c|c|c|c|c|}
\hline & 1998 & 1999 & 2000 & 2001 & 2002 & 2003 & 2004 & 2005 & 2006 & 2007 & P-value \\
\hline & \multicolumn{11}{|c|}{$\mathrm{n}, \%^{*}, \mathrm{P}$-value for $\chi^{2}$ for trends and F-test (beds) } \\
\hline ALL DEATHS & 66481 & 66946 & 66728 & 65555 & 67123 & 68278 & 65050 & 65617 & 64560 & 65435 & \\
\hline \multicolumn{12}{|l|}{ CAUSE OF DEATH } \\
\hline Cancer & $27.6 \%$ & $27.0 \%$ & $26.9 \%$ & $27.2 \%$ & $27.1 \%$ & $26.4 \%$ & $27.1 \%$ & $27.4 \%$ & $28.1 \%$ & $28.4 \%$ & $P<0.001$ \\
\hline Cardiovascular Disease & $28.6 \%$ & $28.1 \%$ & $28.7 \%$ & $28.5 \%$ & $28.1 \%$ & $27.7 \%$ & $27.9 \%$ & $26.7 \%$ & $25.7 \%$ & $25.7 \%$ & $P<0.001$ \\
\hline Respiratory Disease & $11.4 \%$ & $11.5 \%$ & $11.9 \%$ & $11.5 \%$ & $12.1 \%$ & $12.7 \%$ & $11.7 \%$ & $12.4 \%$ & $11.6 \%$ & $11.7 \%$ & $P=0.004$ \\
\hline Disease of Nervous System & $2.3 \%$ & $2.2 \%$ & $2.3 \%$ & $2.3 \%$ & $2.5 \%$ & $2.9 \%$ & $2.6 \%$ & $2.9 \%$ & $3.3 \%$ & $3.4 \%$ & $P<0.001$ \\
\hline Stroke (CVA) & $8.9 \%$ & $9.1 \%$ & $8.7 \%$ & $8.8 \%$ & $8.7 \%$ & $8.4 \%$ & $8.6 \%$ & $8.1 \%$ & $8.0 \%$ & $7.9 \%$ & $P<0.001$ \\
\hline Other & $21.1 \%$ & $22.1 \%$ & $21.5 \%$ & $21.8 \%$ & $21.5 \%$ & $22.0 \%$ & $22.1 \%$ & $22.5 \%$ & $23.2 \%$ & $23.0 \%$ & $P<0.001$ \\
\hline PALLIATIVE SUBSET[16](N = 354 794) & $54.2 \%$ & $53.4 \%$ & $52.8 \%$ & $53.2 \%$ & $53.4 \%$ & $52.9 \%$ & $53.3 \%$ & $53.4 \%$ & $54.5 \%$ & $55.1 \%$ & $P<0.001$ \\
\hline \multicolumn{12}{|l|}{ AGE } \\
\hline 1-64 year & $17.9 \%$ & $18.0 \%$ & $17.8 \%$ & $17.7 \%$ & $17.1 \%$ & $16.5 \%$ & $16.7 \%$ & $16.7 \%$ & $16.8 \%$ & $17.0 \%$ & $P<0.001$ \\
\hline 65-74 year & $21.0 \%$ & $20.0 \%$ & $19.9 \%$ & $19.4 \%$ & $18.6 \%$ & $18.3 \%$ & $17.8 \%$ & $17.7 \%$ & $16.8 \%$ & $16.2 \%$ & $P<0.001$ \\
\hline 75-84 year & $30.4 \%$ & $30.1 \%$ & $30.1 \%$ & $31.0 \%$ & $32.7 \%$ & $34.3 \%$ & $35.9 \%$ & $35.1 \%$ & $35.2 \%$ & $34.4 \%$ & $P<0.001$ \\
\hline $85+$ year & $30.6 \%$ & $31.9 \%$ & $32.2 \%$ & $31.9 \%$ & $31.5 \%$ & $30.9 \%$ & $29.6 \%$ & $30.5 \%$ & $31.2 \%$ & $32.4 \%$ & $P=0.2$ \\
\hline \multicolumn{12}{|l|}{ SEX } \\
\hline Male & $49.9 \%$ & $49.9 \%$ & $50.0 \%$ & $49.9 \%$ & $49.5 \%$ & $49.1 \%$ & $49.6 \%$ & $49.5 \%$ & $49.6 \%$ & $49.7 \%$ & $P=0.04$ \\
\hline Female & $50.1 \%$ & $50.1 \%$ & $50.0 \%$ & $50.1 \%$ & $50.5 \%$ & $50.9 \%$ & $50.4 \%$ & $50.5 \%$ & $50.4 \%$ & $50.3 \%$ & $P=0.04$ \\
\hline \multicolumn{12}{|l|}{ EDUCATIONAL ATTAINMENT } \\
\hline No formal or elementary & $44.3 \%$ & $44.8 \%$ & $43.3 \%$ & $40.7 \%$ & $39.0 \%$ & $36.6 \%$ & $34.7 \%$ & $33.2 \%$ & $31.5 \%$ & $30.0 \%$ & $P<0.001$ \\
\hline Lower secondary & $17.4 \%$ & $17.4 \%$ & $17.7 \%$ & $19.0 \%$ & $18.9 \%$ & $17.6 \%$ & $18.3 \%$ & $18.8 \%$ & $18.7 \%$ & $17.3 \%$ & $P<0.001$ \\
\hline Higher secondary & $10.4 \%$ & $9.4 \%$ & $10.2 \%$ & $9.7 \%$ & $9.2 \%$ & $9.0 \%$ & $9.8 \%$ & $11.5 \%$ & $12.8 \%$ & $13.1 \%$ & $P<0.001$ \\
\hline Higher & $4.5 \%$ & $4.2 \%$ & $3.9 \%$ & $4.1 \%$ & $4.1 \%$ & $3.7 \%$ & $4.1 \%$ & $4.2 \%$ & $4.4 \%$ & $4.5 \%$ & $P=0.03$ \\
\hline Other or unknown & $23.4 \%$ & $24.2 \%$ & $24.8 \%$ & $26.6 \%$ & $28.8 \%$ & $33.0 \%$ & $33.1 \%$ & $32.3 \%$ & $32.5 \%$ & $35.2 \%$ & $P<0.001$ \\
\hline \multicolumn{12}{|l|}{ LIVING ARRANGEMENT } \\
\hline Living alone & $21.6 \%$ & $21.0 \%$ & $20.9 \%$ & $21.4 \%$ & $21.2 \%$ & $20.7 \%$ & $21.6 \%$ & $22.7 \%$ & $22.3 \%$ & $23.4 \%$ & $P<0.001$ \\
\hline Multi-person household & $54.4 \%$ & $54.7 \%$ & $54.8 \%$ & $54.0 \%$ & $53.1 \%$ & $53.0 \%$ & $53.1 \%$ & $51.6 \%$ & $52.3 \%$ & $51.9 \%$ & $P<0.001$ \\
\hline Care home & $24.0 \%$ & $24.2 \%$ & $24.3 \%$ & $24.7 \%$ & $25.6 \%$ & $26.2 \%$ & $25.4 \%$ & $25.7 \%$ & $25.4 \%$ & $24.6 \%$ & $P<0.001$ \\
\hline \multicolumn{12}{|l|}{ URBANIZATION LEVEL } \\
\hline Very strong & $39.3 \%$ & $39.1 \%$ & $38.8 \%$ & $38.4 \%$ & $38.5 \%$ & $38.1 \%$ & $38.1 \%$ & $37.7 \%$ & $37.4 \%$ & $36.4 \%$ & $P<0.001$ \\
\hline Strong & $27.9 \%$ & $27.9 \%$ & $28.1 \%$ & $28.1 \%$ & $28.3 \%$ & $28.2 \%$ & $28.2 \%$ & $28.5 \%$ & $28.4 \%$ & $29.7 \%$ & $P<0.001$ \\
\hline Average & $28.5 \%$ & $28.7 \%$ & $28.7 \%$ & $29.1 \%$ & $28.8 \%$ & $29.2 \%$ & $29.4 \%$ & $29.4 \%$ & $29.9 \%$ & $29.4 \%$ & $P<0.001$ \\
\hline Low or rural & $4.3 \%$ & $4.3 \%$ & $4.4 \%$ & $4.4 \%$ & $4.4 \%$ & $4.4 \%$ & $4.3 \%$ & $4.5 \%$ & $4.4 \%$ & $4.5 \%$ & $P=0.12$ \\
\hline \multicolumn{12}{|l|}{ HEALTH CARE RESOURCES } \\
\hline Hospital beds/1000 & 5.5 & 5.4 & 5.5 & 5.6 & 5.6 & 5.6 & 5.5 & 5.4 & 5.4 & 5.3 & $P=1$ \\
\hline Residential beds in care homes/1000 $\geq 65 \mathrm{y}$ & 56.0 & 52.9 & 49.9 & 46.6 & 43.3 & 40.2 & 38.2 & 37.7 & 36.6 & 35.7 & $P<0.001$ \\
\hline Skilled nursing beds in care homes $/ 1000 \geq 65 \mathrm{y}$ & 11.6 & 14.5 & 17.5 & 20.2 & 22.8 & 25.4 & 26.9 & 26.8 & 27.8 & 29.0 & $P<0.001$ \\
\hline
\end{tabular}

* Presented percentages are column percentages.

Table 2 Trends in Place of Death (aged $\geq 1$ y) 1998-2007 ( $N=661771$ )

\begin{tabular}{|c|c|c|c|c|c|c|c|c|c|c|c|}
\hline \multirow[b]{2}{*}{ PLACE OF DEATH } & 1998 & 1999 & 2000 & 2001 & 2002 & 2003 & 2004 & 2005 & 2006 & 2007 & P-value \\
\hline & \multicolumn{11}{|c|}{$\mathrm{n}, \%^{*}, \mathrm{P}$-value for $\chi^{2}$ for trends } \\
\hline \multirow[t]{2}{*}{ Home } & 15311 & 15389 & 15226 & 14919 & 15075 & 15287 & 14912 & 14878 & 14760 & 14726 & $P=0.4$ \\
\hline & $23.0 \%$ & $23.0 \%$ & $22.8 \%$ & $22.8 \%$ & $22.5 \%$ & $22.4 \%$ & $22.9 \%$ & $22.7 \%$ & $22.9 \%$ & $22.5 \%$ & \\
\hline \multirow[t]{2}{*}{ Hospital } & 36631 & 36283 & 35924 & 34964 & 35227 & 35574 & 34059 & 34085 & 33264 & 33856 & $P<0.001$ \\
\hline & $55.1 \%$ & $54.2 \%$ & $53.8 \%$ & $53.3 \%$ & $52.5 \%$ & $52.1 \%$ & $52.4 \%$ & $51.9 \%$ & $51.5 \%$ & $51.7 \%$ & \\
\hline \multirow[t]{2}{*}{ Care home } & 12161 & 12980 & 13328 & 13375 & 14578 & 15363 & 14209 & 14605 & 14469 & 14792 & $P<0.001$ \\
\hline & $18.3 \%$ & $19.4 \%$ & $20.0 \%$ & $20.4 \%$ & $21.7 \%$ & $22.5 \%$ & $21.8 \%$ & $22.3 \%$ & $22.4 \%$ & $22.6 \%$ & \\
\hline \multirow[t]{2}{*}{ Other } & 2378 & 2293 & 2250 & 2297 & 2242 & 2054 & 1870 & 2049 & 2067 & 2061 & $P<0.001$ \\
\hline & $3.6 \%$ & $3.4 \%$ & $3.4 \%$ & $3.5 \%$ & $3.3 \%$ & $3.0 \%$ & $2.9 \%$ & $3.1 \%$ & $3.2 \%$ & $3.1 \%$ & \\
\hline
\end{tabular}



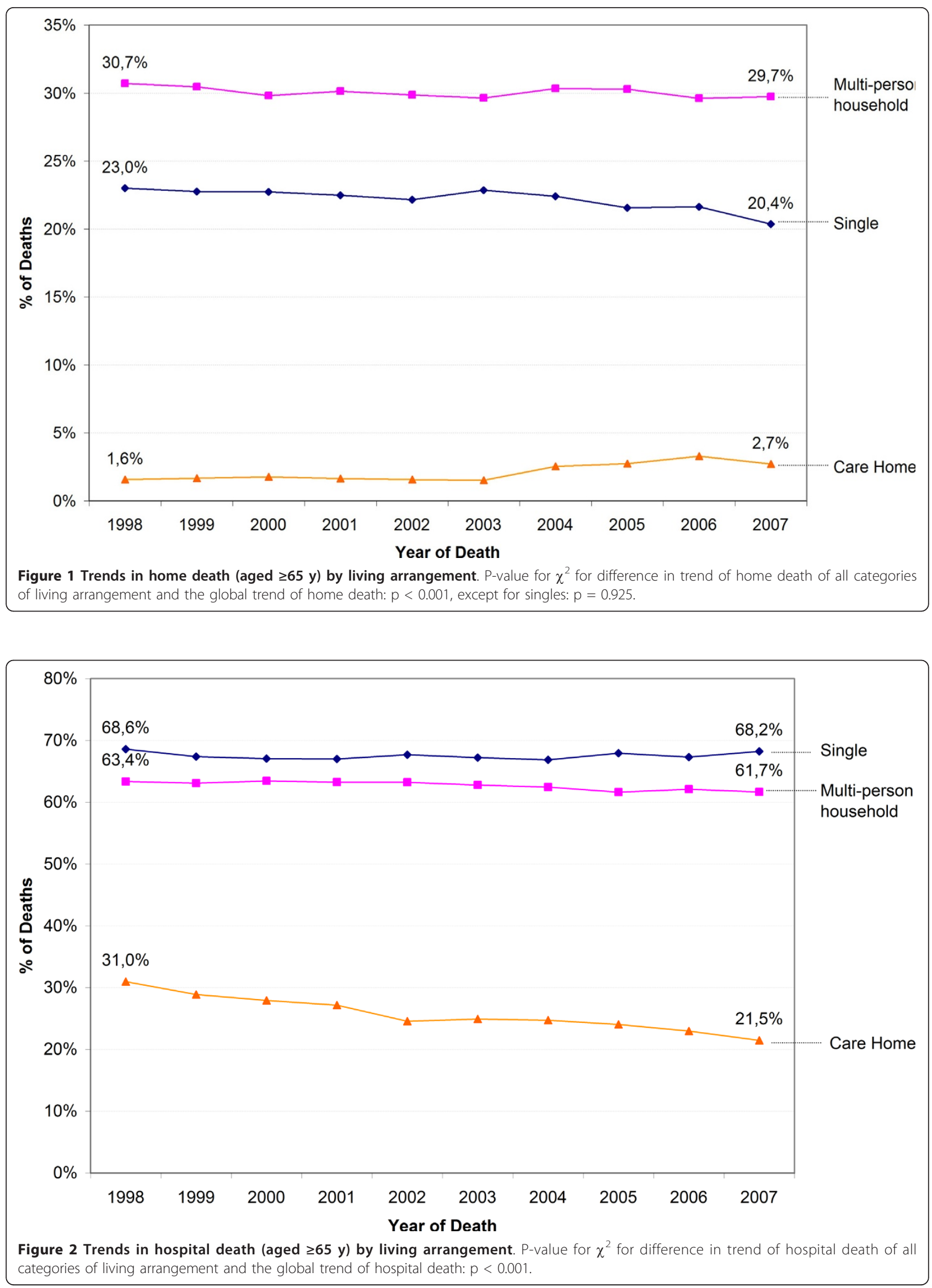


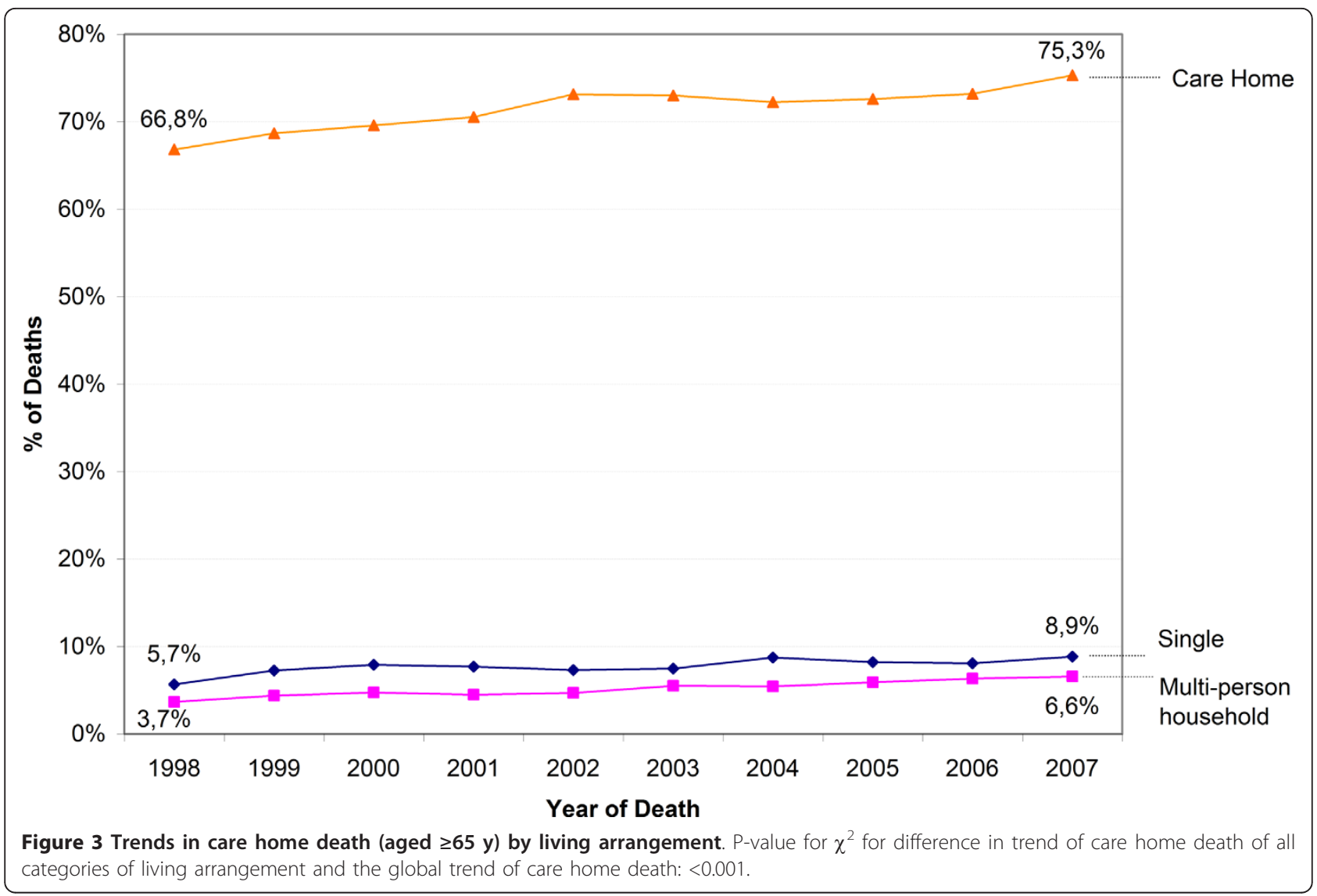

the decreasing odds of dying in hospital. In our final model, the chance of dying out of hospital of those living in care homes was still more likely in each year of the study period compared to 1998, except in 1999-2001 and 2004, (Table 3) and was more likely for those who died from non-cancer conditions, with a higher age, females, having a lower or unknown educational attainment and living in healthcare regions with less residential beds and more skilled nursing beds in care homes and more hospital beds.(Table 4)

Mortality (aged $\geq 1$ year) is expected to rise from 65 435 in 2007 to 83388 in 2040. The first scenario (S1), in which the age-and sex-specific distribution of place of death of 2007 was projected, shows an increase of both care home (from 14792 in 2007 to 26030 in 2040) and hospital deaths (from 33856 to 39 714) (Figure 4). The number of deaths at home would rise slightly from 14 726 to 15954 ). The second scenario (S2), for which we projected the 10 year trends forward to 2040, shows an increase in care home deaths to 35545 . Deaths at home and in hospital show a slight decrease to 13380 and 33 076. In 2038, the proportion of care home deaths (41.15\%) would exceed that of hospital deaths (40.53\%) (data not shown). The proportion of deaths at home would drop from $22.5 \%$ in 2007 to $16.05 \%$ in 2040 .

\section{Discussion}

In Belgium in the period 1998-2007 the proportion of deaths in hospitals decreased and in care homes increased, while that of home deaths remained stable. The proportion of care home residents dying in hospitals dropped from $31.0 \%$ in 1998 to $21.5 \%$ in 2007 . The trend of declining chances of dying in hospital of care home residents was largely related to the substitution of residential beds by skilled nursing beds in care homes. The odds of dying in hospital of those living at home did not diminish during the study period. Continuation of the trends in place of death during 1998-2007 would lead to more than double the number of care home deaths by 2040 and to a larger proportion of deaths in care homes than in hospitals.

For the first time trends in place of death were studied and related not only to shifts in underlying cause of death, age and sex of the deceased population, but also to changes in living arrangements, educational attainment, urbanization levels of the place of residence and availability of beds in hospitals and care homes. Trends in place of death proved to be related to changes in care levels in care homes. In contrast with previous research, our study considered all patients in all care settings over a 10 year period. Trends in place of death have not 
Table 3 Unadjusted and adjusted trends in chance of dying at home and in care homes of patients (aged $\geq 65$ y) who died of chronic life-limiting conditions 1998-2007

\begin{tabular}{|c|c|c|c|c|c|c|c|c|c|c|}
\hline & 1998 & 1999 & 2000 & 2001 & 2002 & 2003 & 2004 & 2005 & 2006 & 2007 \\
\hline $\begin{array}{l}\text { PATIENTS LIVING AT HOME } \\
(\mathrm{N}=189884)\end{array}$ & \multicolumn{10}{|c|}{ OR of Home Death vs. Hospital Death $(99 \% \mathrm{Cl})$} \\
\hline Unadjusted odds ratios & \multicolumn{10}{|c|}{$N S^{*}$} \\
\hline Adjusted odds ratiost & \multicolumn{10}{|c|}{$N S^{*}$} \\
\hline $\begin{array}{l}\text { PATIENTS LIVING IN CARE HOMES } \\
(\mathrm{N}=79846)\end{array}$ & \multicolumn{10}{|c|}{ OR of Care Home Death vs. Hospital Death $(99 \% \mathrm{Cl})$} \\
\hline Unadjusted odds ratios & Ref & $\begin{array}{c}1.14 \\
(1.03-1.25)\end{array}$ & $\begin{array}{c}1.19 \\
(1.08-1.31)\end{array}$ & $\begin{array}{c}1.24 \\
(1.13-1.36)\end{array}$ & $\begin{array}{c}1.44 \\
(1.31-1.59)\end{array}$ & $\begin{array}{c}1.47 \\
(1.34-1.62)\end{array}$ & $\begin{array}{c}1.46 \\
(1.32-1.61)\end{array}$ & $\begin{array}{c}1.50 \\
(1.36-1.66)\end{array}$ & $\begin{array}{c}1.52 \\
(1.38-1.68)\end{array}$ & $\begin{array}{c}1.65 \\
(1.50-1.83)\end{array}$ \\
\hline Adjusted odds ratios $\neq$ & Ref & $\begin{array}{c}1.08 \\
(0.98-1.19)\end{array}$ & $\begin{array}{c}1.06 \\
(0.96-1.17)\end{array}$ & $\begin{array}{c}1.05 \\
(0.95-1.17)\end{array}$ & $\begin{array}{c}1.17 \\
(1.05-1.31)\end{array}$ & $\begin{array}{c}1.15 \\
(1.03-1.29)\end{array}$ & $\begin{array}{c}1.11 \\
(0.99-1.25)\end{array}$ & $\begin{array}{c}1.15 \\
(1.03-1.30)\end{array}$ & $\begin{array}{c}1.14 \\
(1.01-1.29)\end{array}$ & $\begin{array}{c}1.21 \\
(1.07-1.37)\end{array}$ \\
\hline
\end{tabular}

* The variable Year of Death was not selected in the forward stepwise likelihood ratio selection procedure of variables in the logistic regression analysis. † Odds ratios adjusted for underlying cause of death, age, sex, education, living arrangement, urbanization level and available hospital beds. Odds ratios of covariates are reported in Table 4.

‡ Odds ratios adjusted for underlying cause of death, age, sex, education, urbanization level, available residential beds and skilled nursing beds in care homes, and available hospital beds. Odds ratios of covariates are reported in Table 4.

Table 4 Adjusted odds ratio's of covariates in the logistic regression models of home death versus hospital death and care home death versus hospital death (table 3) of patients (aged $\geq 65 \mathrm{y}$ ) who died of chronic life-limiting conditions 1998-2007

\begin{tabular}{|c|c|c|}
\hline & $\begin{array}{l}\text { PATIENTS LIVING AT HOME } \\
(\mathrm{N}=189884)\end{array}$ & $\begin{array}{l}\text { PATIENTS LIVING IN CARE HOMES } \\
\qquad(\mathrm{N}=79846)\end{array}$ \\
\hline & $\begin{array}{l}\text { AOR of Home Death vs. } \\
\text { Hospital Death }(99 \% \mathrm{Cl})\end{array}$ & $\begin{array}{l}\text { AOR of Care Home Death vs. } \\
\text { Hospital Death }(99 \% \mathrm{Cl})\end{array}$ \\
\hline \multicolumn{3}{|l|}{ CAUSE OF DEATH } \\
\hline Cancer & Reference & Reference \\
\hline Non-cancer & $0.86(0.83-0.88)$ & $1.09(1.04-1.15)$ \\
\hline \multicolumn{3}{|l|}{ AGE } \\
\hline 65-74 year & Reference & Reference \\
\hline 75-84 year & $0.99(0.96-1.02)$ & $1.51(1.40-1.64)$ \\
\hline $85+$ year & $1.26(1.22-1.31)$ & $2.18(2.01-2.36)$ \\
\hline SEX & $N S^{*}$ & \\
\hline Male & & Reference \\
\hline Female & & $1.13(1.09-1.18)$ \\
\hline EDUCATION & $N S^{*}$ & \\
\hline Low-unknown/other & & $1.19(1.09-1.29)$ \\
\hline Higher secondary/Higher & & Reference \\
\hline LIVING ARRANGEMENT & & $\dagger$ \\
\hline Living alone & Reference & \\
\hline Multi-person Household & $1.95(1.89-2.01)$ & \\
\hline URBANIZATION & & $N S^{*}$ \\
\hline Very Strong/Strong & Reference & \\
\hline Moderate/Low & $1.42(1.38-1.46)$ & \\
\hline $\begin{array}{l}\text { RESIDENTIAL BEDS IN CARE HOMES } \\
\text { (Continuous per } 1 \text { bed/1000 } \geq 65 \text { ) }\end{array}$ & t & $0.997(0.996-0.999)$ \\
\hline $\begin{array}{l}\text { NURSING BEDS IN CARE HOMES } \\
\text { (Continuous per } 1 \text { bed/1000 } \geq 65 \text { ) }\end{array}$ & $\dagger$ & $1.015(1.012-1.018)$ \\
\hline HOSPITAL BEDS (Continuous per 1 bed/1000) & $0.896(0.884-0.910)$ & $1.033(1.006-1.061)$ \\
\hline
\end{tabular}

*: Not significant. The variable was not selected in the forward stepwise likelihood ratio selection procedure of variables in the logistic regression analysis.

†: Variable was not included in the model. 


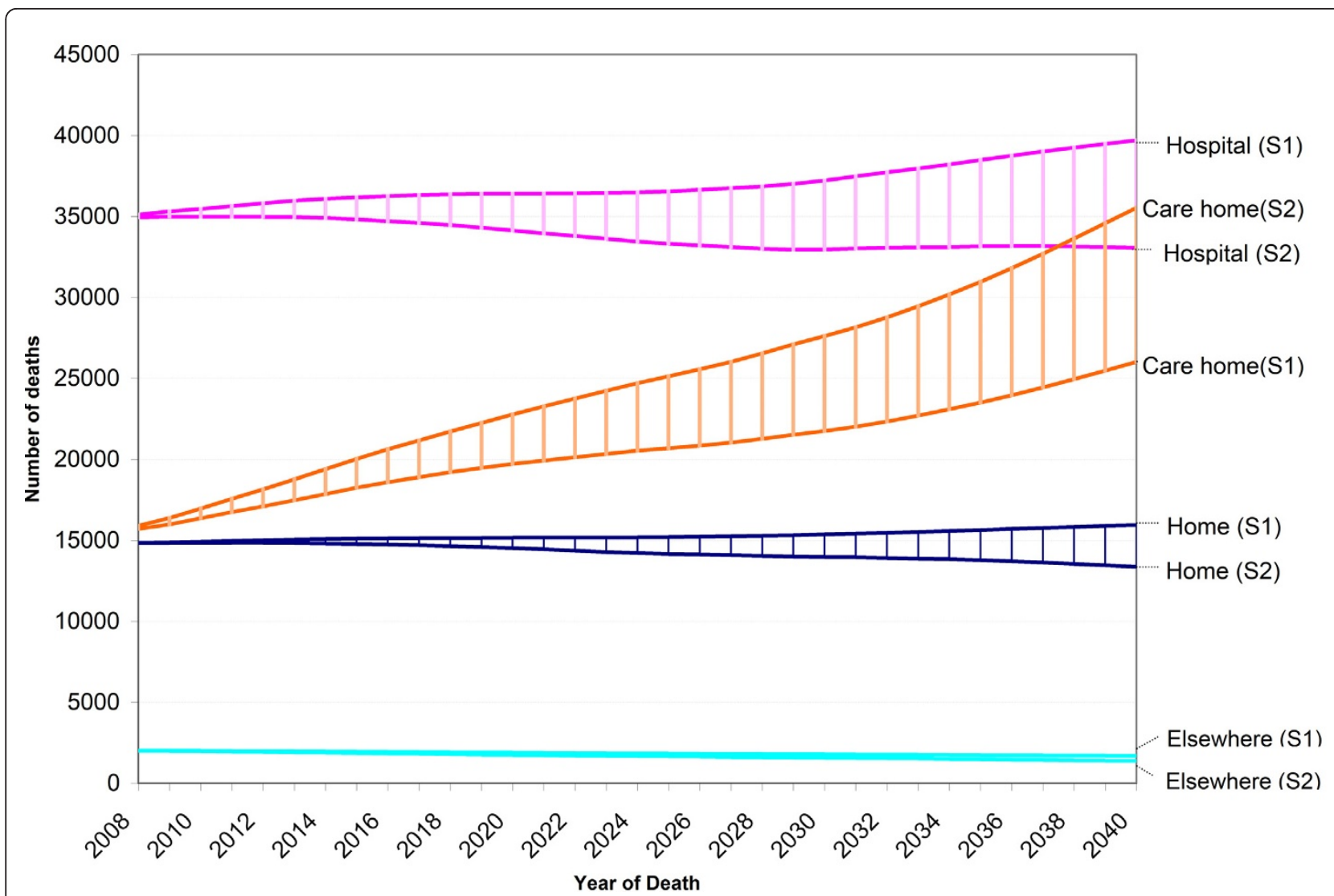

Figure 4 Projected trends in proportion of home deaths, hospital deaths and care home deaths (2008-2040), based on 2 scenarios. Age- and sex-specific mortality projections of the Belgian National Planning Bureau were used to perform linear projections of numbers of deaths from 2008 to 2040 in all care settings starting from the age- and sex-specific proportions of deaths in the different care settings in the period 1998-2007. Two scenarios were considered. In scenario 1 (S1) future trends in place of death were projected starting from the age- and sex- specific distribution of place of death in 2007. In scenario 2 (S2) the projection was based on the age- and sex-specific percentage point change in place of death from 1998 to 2007.

been studied in continental Europe before. Potential limitations of this study are connected to the use of death certificate data: possible unreliability of the certification and coding of some underlying diseases and sociodemographic information, missing values for variables related to the background of the deceased and the lack of information on factors which affect place of death $[28,29]$. Multilevel modelling may have been an alternative appropriate approach to analyze data related to individuals and geographical areas.

Patterns in the previous century showed an increasing hospitalization of death. Concentration of health care in hospitals and the reduced availability of informal care givers due to sociodemographic and economic developments lead to a growing number of hospital deaths, and the proportion of deaths occurring at home decreased from more than half to a quarter or less [30,31]. From the 1980s onwards a decrease in hospital deaths was observed in many countries, both in cancer and non-cancer patients
$[11,12,14,15,17,20,21,23,32]$. In many countries, this trend was not balanced by an increase in home deaths [18-20], even in cancer patients $[11,14,15]$, because of the ongoing sociodemographic and economic dynamics that caused the hospitalization of death trend in the first part of the century, and the growing availability of other care options for end-of-life care, hospices in some countries and care homes in others. In consequence the proportion of care home deaths in the UK, Canada, USA, and Australia increased in the last twenty years of the previous century by $4 \%$ to $10 \%[11,17,20,21,23]$. In our findings additional care options in care homes supported shifts in place of death in Belgium. The additional availability of skilled nursing care beds in care homes replacing residential beds resulted in a considerable growth of care home deaths, especially among existing residents. The latter is not obvious, in light of the large-scale transfer of care home residents to hospital at the end of life observed previously $[33,34]$. Because of the shift towards skilled nursing care 
beds the odds of care home residents dying in hospital decreased drastically in a period of only ten years. The trend of decreasing hospital death risk of care home residents remained significant after adjusting for available skilled nursing beds in care homes. Therefore this trend is not just a consequence of an increase in skilled nursing resources but probably also of the development of palliative care in care homes. From 1997 onwards in-house palliative care reference persons responsible for supporting, coaching and educating care givers were appointed [9]. Involvement of these palliative care reference persons is probably associated with reduced odds of dying in hospital of care home residents since supporting out-of-hospital death is one of there main objectives [9] and with the rapid development of policies on advance care planning in Flemish care homes from 2000 onwards, resulting in a donot-hospitalize option available in $90 \%$ of care homes by 2006 [35].

The implications of our findings are considerable. Between 1998 and 2007 an increase of more than 20 000 skilled nursing beds in care homes, replacing residential beds, succeeded in reducing the hospitalization risk of care home residents and to some extent of older patients living at home. Further reducing that risk during the coming decades or even maintaining it at the 2007 level, in the context of a rapidly ageing population and a rapidly growing number of deaths, will require a massive investment in skilled nursing home beds and other end-of-life care options outside hospitals; care homes could become the central location for end-of-life care in Belgium in the future, replacing private residences in the first part of the $20^{\text {th }}$ century and hospitals thereafter. The economic implications of this trend are very important and should be considered. Governments should provide sufficient skilled nursing resources in care homes to respect patients' preferences and needs.

Even if the facilities are present, providing quality endof-life care in care homes will require a palliative care approach and additional investment in palliative care services as treatment of pain and symptoms is often poor and communication about the needs and preferences of terminally ill care home residents is inadequate, due to insufficient staffing, lack of time and resources and inadequate financial reimbursement of palliative care costs from healthcare insurance [36-38]. Future research should examine if and how quality of care at the end of life has changed with the changing place of death.

\section{Conclusions}

We found that in Belgium between 1998 and 2007 the proportion of deaths in hospitals decreased $(-3.4 \%)$ and increased in care homes $(+4.3 \%)$, while that of home deaths remained stable. This trend was largely explained by the proportion of care home residents dying in hospitals dropping from $31 \%$ to $21.5 \%$, a shift strongly related to the substitution of residential beds by skilled nursing beds in care homes. Continuation of this trend would lead to more than double the number of care home deaths by 2040. The implications of our findings are considerable. Care homes may become the main locus of end-of-life care in the future and governments should provide sufficient skilled nursing resources in care homes to fulfil the preferences and needs of their residents.

\section{Acknowledgements and funding}

We acknowledge the Flemish Agency for Care and Health and the Brussels Health and Social Observatory for providing the death certificate data used in this study.

This work was supported by the Vrije Universiteit Brussel, Brussels, Belgium. The Vrije Universiteit Brussel did not play any role in the study design; in the collection, analysis and interpretation of data; in the writing of the manuscript; and in the decision to submit the manuscript for publication.

\section{Author details}

'Vrije Universiteit Brussel, End-of-Life Care Research Group Ghent University \& Vrije Universiteit Brussel, Laarbeeklaan 103, 1090 Brussels, Belgium. ${ }^{2}$ Vrije Universiteit Brussel, Interface demography, Pleinlaan 2, 1050 Brussels, Belgium. ${ }^{3}$ Department of Public and Occupational Health, EMGO Institute for Health and Care Research and Palliative Care Center of Expertise, VU University Medical Center, Van der Boechorststraat 7, 1081 BT Amsterdam, the Netherlands.

\section{Authors' contributions}

$\mathrm{DH}$ and JC performed the statistical analyses and drafted the manuscript. All authors participated in the conception and design of the study, the acquisition of data, the interpretation of data, revising the manuscript critically for important intellectual content, and have given final approval of the version of the manuscript to be published.

\section{Declaration of competing interests}

The authors declare that they have no competing interests.

Received: 27 September 2010 Accepted: 13 April 2011 Published: 13 April 2011

\section{References}

1. Gott M, Seymour J, Bellamy G, Clark D, Ahmedzai S: Older people's views about home as a place of care at the end of life. Palliat Med 2004, 18:460-467.

2. Wolff $J$, Kasper JD, Shore AD: Long-term care preferences among older adults: a moving target? J Aging Soc Policy 2008, 20:182-200.

3. Lo JC: The impact of hospices on health care expenditures-the case of Taiwan. Soc Sci Med 2002, 54:981-991.

4. Chappell NL, Dlitt BH, Hollander MJ, Miller JA, McWilliam C: Comparative costs of home care and residential care. Gerontologist 2004, 44:389-400.

5. Houttekier D, Cohen J, Bilsen J, Deboosere P, Verduyckt P, Deliens L: Determinants of the place of death in the Brussels metropolitan region. J Pain Symptom Manage 2009, 37:996-1005.

6. Cohen J, Bilsen J, Hooft P, Deboosere P, van der Wal G, Deliens L: Dying at home or in an institution using death certificates to explore the factors associated with place of death. Health Policy 2006, 78:319-329.

7. Cohen J, Houttekier D, Onwuteaka-Philipsen B, Miccinesi G, AddingtonHall J, Kaasa S, et al: Which patients with cancer die at home? A study of six European countries using death certificate data. J Clin Oncol 2010, 28:2267-2273.

8. House of Commons Health Committee. Palliative Care [http://www. publications.parliament.uk/pa/cm200304/cmselect/cmhealth/454/45402. htm], Fourth Report of Session 2003-04. Available at: Accessed: July 14, 2010 
9. Federal Evaluation Commission of Palliative Care: Evaluation Report of Palliative Care Brussels: Federal Public Service of Health, Food Chain Safety and Environment; 2008 [http://mailsystem.palliatief.be/accounts/15/ attachments/rapporten/fed_evaluatiecel_mai_2008_rapport_2008_nl.pdf], [in Dutch]. Available at: Accessed: July 14, 2010

10. Centeno C, Clark D, Lynch T, Racafort J, Praill D, De Lima L, et al: Facts and indicators on palliative care development in 52 countries of the WHO European region: results of an EAPC Task Force. Palliat Med 2007, 21:463-471.

11. Davies $\mathrm{E}$, Linklater $\mathrm{KM}$, Jack RH, Clark L, Moller $\mathrm{H}$ : How is place of death from cancer changing and what affects it? Analysis of cancer registration and service data. $\mathrm{Br} J$ Cancer 2006, 95:593-600

12. Neutel Cl, Bishop ML, Harper SD, Gaudette LA: Proportion of cancer deaths occurring in hospital, Canada, 1994-2000. Can J Public Health 2005, 96:264-268.

13. Hunt RW, Fazekas BS, Luke CG, Roder DM: Where patients with cancer die in South Australia, 1990-1999: a population-based review. Med J Aust 2001, 175:526-529.

14. Higginson IJ, Astin P, Dolan S: Where do cancer patients die? Ten-year trends in the place of death of cancer patients in England. Palliat Med 1998, 12:353-363.

15. Hunt $R$, Bonett $A$, Roder $D$ : Trends in the terminal care of cancer patients: South Australia, 1981-1990. Aust N Z J Med 1993, 23:245-251.

16. van der Velden $L$, Francke $A L$, Hingstman L, Willems DL: Dying from cancer or other chronic diseases in the Netherlands: ten-year trends derived from death certificate data. BMC Palliat Care 2009, 8:4

17. Wilson DM, Truman CD, Thomas R, Fainsinger $R$, Kovacs-Burns $K$, Froggatt $K$ et al: The rapidly changing location of death in Canada, 1994-2004. SoC Sci Med 2009, 68:1752-1758.

18. Gomes B, Higginson IJ: Where people die (1974-2030): past trends, future projections and implications for care. Palliat Med 2008, 22:33-41.

19. Yang L, Sakamoto N, Marui E: A study of home deaths in Japan from 1951 to 2002. BMC Palliat Care 2006, 5:2.

20. Ahmad S, O'Mahony MS: Where older people die: a retrospective population-based study. QJM 2005, 98:865-870.

21. Flory J, Yinong YX, Gurol I, Levinsky N, Ash A, Emanuel E: Place of death: U. S. trends since 1980. Health Aff (Millwood) 2004, 23:194-200.

22. Wilson DM, Northcott HC, Truman CD, Smith SL, Anderson MC, Fainsinger RL, et al: Location of death in Canada. A comparison of 20thcentury hospital and nonhospital locations of death and corresponding population trends. Eval Health Prof 2001, 24:385-403.

23. Brameld KJ, Holman CD, Bass AJ, Codde JP, Rouse IL: Hospitalisation of the elderly during the last year of life: an application of record linkage in Western Australia 1985-1994. J Epidemiol Community Health 1998, 52:740-744.

24. Clark D, ten Have $H$, Janssens $R$ : Common threads? Palliative care service developments in seven European countries. Palliat Med 2000, 14:479-490.

25. Flemish Agency for Care and Health: Death certificates of persons of one year and older. [in Dutch] [http://www.zorg-en-gezondheid.be/data_sterfte. aspx], Available at: Accesed: July 13, 2010

26. Van Hecke E: Developing a policy instrument to manage the programming, planning and implementationof care and welfare facilities. [In Dutch]. Leuven: K.U.Leuven Institute for Social and Economic Geography; 2001.

27. Federal Planning Bureau Directorate of Statistics and Economic Information. Population Projections 2007-2060 [In Dutch]. Brussels: Federal Planning Bureau Directorate of Statistics and Economic Information; 2008.

28. Gomes B, Higginson IJ: Factors influencing death at home in terminally ill patients with cancer: systematic review. BMJ 2006, 332:515-521.

29. Tang ST, McCorkle R: Determinants of place of death for terminal cancer patients. Cancer Invest 2001, 19:165-180.

30. Hunt RW, Bond MJ, Groth RK, King PM: Place of death in South Australia. Patterns from 1910 to 1987. Med J Aust 1991, 155:549-553.

31. Wilson DM, Smith SL, Anderson MC, Northcott HC, Fainsinger RL, Stingl MJ, et al: Twentieth-century social and health-care influences on location of death in Canada. Can J Nurs Res 2002, 34:141-161.

32. Burge F, Lawson B, Johnston G: Trends in the place of death of cancer patients, 1992-1997. CMAJ 2003, 168:265-270.
33. Van den Block L, Deschepper R, Bilsen J, Van Casteren V, Deliens L: Transitions between care settings at the end of life in belgium. JAMA 2007, 298:1638-1639

34. Menec VH, Nowicki S, Blandford A, Veselyuk D: Hospitalizations at the end of life among long-term care residents. J Gerontol A Biol Sci Med Sci 2009, 64:395-402.

35. De Gendt C, Bilsen J, Vander Stichele R, Deliens L: Nursing home policies regarding advance care planning in Flanders, Belgium. Eur J Public Health 2010, 20:189-194.

36. Teno JM: Now is the time to embrace nursing homes as a place of care for dying persons. J Palliat Med 2003, 6:293-296.

37. Brazil K, Krueger P, Bedard M, Kelley L, McAiney C, Justice C, et al: Quality of care for residents dying in Ontario long-term care facilities: findings from a survey of directors of care. J Palliat Care 2006, 22:18-25.

38. Brazil K, Bedard M, Krueger P, Taniguchi A, Kelley ML, McAiney C, et al: Barriers to providing palliative care in long-term care facilities. Can Fam Physician 2006, 52:472-473.

\section{Pre-publication history}

The pre-publication history for this paper can be accessed here: http://www.biomedcentral.com/1471-2458/11/228/prepub

doi:10.1186/1471-2458-11-228

Cite this article as: Houttekier et al: Study of recent and future trends in place of death in Belgium using death certificate data: a shift from hospitals to care homes. BMC Public Health 2011 11:228.

\section{Submit your next manuscript to BioMed Central and take full advantage of:}

- Convenient online submission

- Thorough peer review

- No space constraints or color figure charges

- Immediate publication on acceptance

- Inclusion in PubMed, CAS, Scopus and Google Scholar

- Research which is freely available for redistribution

Submit your manuscript at www.biomedcentral.com/submit
C) Biomed Central 